\title{
Problems and Countermeasures of the Inheritance and Development of Ethnic Minorities Traditional Sports Culture
}

\author{
Qiang Chen \\ Nanchang Institute of Science \&Technology, Nanchang 330108, China
}

\begin{abstract}
Minority traditional sports culture is an important component of minority culture. It is assumed as a kind of cultural symbol or cultural activity, it contains the national spirit, the value identity, the psychological mode and the mode of production and life. The minority traditional sports culture development in the presence of attach importance to competitive rationalism and despise the mass rationalism, attach importance to form, attention to the traditional connotation of modernity and ethnic traditional sports inheritance, get no successor, etc.. Therefore we should correctly deal with the impact of sports globalization; the government should play a leading role in constructing the protection, inheritance and development mechanism traditional sports culture; to realize the harmonious development of ethnic minority traditional sports culture; exploring and sorting out the traditional sports, so as to promote the inheritance and development of ethnic minority traditional sports culture.

Keywords: Ethnic Minorities; Traditional Sports Culture; Inheritance And Development
\end{abstract}

\section{Introduction}

The ethnic minority traditional sports culture is an important component of the national traditional culture, it is the historical accumulation of different ethnic groups living in a specific geographical environment, due to differences in living area and living environment and life style of production and dissemination of cultural accumulation, by education, entertainment, fitness, worship and other 
diverse cultural activities constitute the national minority sports culture connotation and characterization system in the historical process of the development of ethnic minorities, although the frequent changes of regime, national minorities continue to die and migration, the minority traditional sports culture in the improvement and inheritance of cultural conflict, constantly communicate with each other, leaving a unique and valuable intangible cultural heritage of the Chinese nation sports.

\section{Problems in the inheritance of ethnic minorities traditional sports culture}

At present, "cultural fever" was prevalent in China, various cultural proposition has become the focus of one after another. Among them, the national culture is the key word of this kind of focus. The research on the national culture and its existence and development in the practice of production and life is one of the core propositions of the "cultural development" in our country. China's national culture connotation includes two basic levels, the one refers to Chinese 5000 years of civilization and traditional culture, the two refers to the national culture and characteristics of various nationalities in China, which is the basic object of the current development of Chinese national culture. Sports culture refers to the composition of minority national sports culture of national traditional culture, it is the product of the specific practice of the nation, specifically refers to reflect the traditional sports of some concepts and ideas, or the expression of traditional sports activities in the form of content and determine or control the activity specification, but in the process of inheritance and development, there are a lot of problems, mainly reflects the lack of cultural connotation and essence of various partial reading and misunderstanding.

China's national traditional sports rooted in the masses, spread in the countryside, with strong agricultural culture characteristics, the history of the nation's compatriots fitness entertainment and social interaction of the main carrier into the 20th century, modern western sports gradually to emphasize competitive in the Olympic Games, fueled by the inexorable trend of modern sports sweeping the world since the 1950s in China, the "nationwide system" policy can be seen everywhere, especially take the Olympic gold medal for the purpose in the development of sports, resulting in long-term slow development of mass sports in China, led to the national traditional sports re-competitive nature and despise the mass of the value orientation. The most typical example is the martial arts, Chinese wrestling, Chinese chess and other traditional sports gradually withdraw from the "Olympic election. At the same time, the National Minority Sports events more and more standardized and competitive in the sports to a certain extent, all of those affected echelon development of the national sports culture, resulting in the entire community neglect of national sports culture.

In addition to the traditional national sports physical attributes, there are 
cultural properties. They are not only the way of fitness, athletics and entertainment, but also the important carriers of religious beliefs, customs, festivals, language dress, national psychology and national culture of the Chinese nation. Since the 1950s, the traditional sports of our country have taken the working mechanism of the sports department supervisor, the civil and the education department affairs commission, which mainly attach importance to the "sports attribute" of the national traditional sports and neglect its "cultural attribute". At the same time, the lack of understanding of the "cultural attributes" has also led to a long debate whether traditional sports are "national sports" or "traditional sports" to a certain extent, affected the development of national traditional sports. Into the $21 \mathrm{st}$ century, the international intangible cultural heritage protection under the influence of a large number of national traditional sports gradually as cultural heritage and an important part of folk culture, which was announced as national, provincial, city, county intangible cultural heritage. In 2011, The National Fitness Program put forward: attach importance to the national folk traditional sports excavation and organize the promotion work, promote the traditional national sports culture, excellent folk traditional sports into the intangible cultural heritage to carry out the national traditional sports education activities, to hold national traditional folk sports show and competition activities, to promote the goal of the national and regional exchanges and expand the national traditional folk sports international influence, the Chinese nation cultural attribute of traditional sports has gradually been paid attention by national laws and policies.

Any kind of culture wants to get an effective heritage and development can not be separated from modern life, the ethnic minority traditional sports culture is no exception. First, the traditional emphasis on the traditional national sports, that the national traditional sports should adhere to the "original ecology" type of protection, fear of national traditional sports modernity will lead to the transformation of its traditional cultural value. This view is used in the cultural heritage of national traditional sports, but in fact, it can not be extended to all national traditional sports. Second, in many places, misunderstanding and improper development of national traditional sports due to lack of knowledge, lack of talent, the traditional national traditional sports protection and modern means are very low, which is lack of innovation. Some places seem to attach great importance to traditional sports, all kinds of competitions activities, but because those activities are lack of innovation, lack of ornamental and influence, regardless of time, regardless of location, regardless of cultural connotation of the national traditional sports development into vulgar Of tourism projects. This kind of copying, deliberately distorting the traditional practice of traditional sports, did not effectively protect the cultural values of national traditional sports, but seriously affected the development of national sports. Third, it is wrong to recognize the modernization of national traditional sports, somebody simply thinks that modernization is competitive, Western and Olympic, so with the modern sports rules of the game to transform the traditional sports. Modernization is first of all the modernization of culture, the modernization of concepts, and the second is the modernization of expression forms and contents. 
Now we are get the "shape" of modernization, while ignoring the " spirit " of modernization.

The heritage and development of ethnic minority traditional sports culture cannot do without talent, lack of special sports talents has become a problem restricting the development of ethnic minorities traditional sports. Some minority youth because of the limited space for development, they chose to leave the hometown, go to large and medium-sized city to seek development opportunities, resulting in the emergence of national traditional sports inheritance phenomenon, minority youth get no successor; some to leave their homeland, imperceptibly accepted the strong culture, gradually weakened the nation's traditional culture. In addition, the local government attaches great importance to ethnic minorities of traditional sports, because the measures are not in place, there is no corresponding incentive mechanism. resulting in the emergence phenomenon of "talk on paper", some minority people have finally given up the nation's traditional sports. The most important is the culture function and compulsory education has not been truly implemented, especially the national cultural heritage and development mission of national education did not really play, education in the cultivation of talents, the "knowledge of universalism" and "statute tool rationality" and the view of culture education should be compressed, the weakening of the cultural mission of education. thus, cultivating of cultural awareness, cultural consciousness and cultural identity and other aspects of people is difficult to achieve results. The survey found that many ethnic minority students, ethnic minority students, they are lack of the region's traditional culture of the awareness and recognition, and lack of the ability to inherit and carry forward the national culture.

\section{Countermeasures of the inheritance and development of ethnic minorities traditional sports culture}

After the comprehensive consideration of ethnic minority traditional sports culture background, basic characteristics, existing problems and the basic way of inheritance, the author proposes the strategy of heritage and development of minority traditional sports cultural from the following aspects.

First, vigorously tap the excellent national traditional sports culture, combine it with the economic development, the reasonable use of the market mechanism, gradually broaden investment channels, actively explore the industrialization of national sports culture, to create an effective market operation mode. Second, strengthen the propaganda and education of national sports culture, improve its social status. On the one hand, bring the national sports culture into school education, creation of knowledge 、 performance、 interesting and relatively strong project, creating reading and cultural education of national sports audio-visual materials, make it become an important content of students' quality education and specialty evaluation, gradually infiltrated into the teaching activities; on the other hand, the extensive development of social education. Using a variety of 
cultural sites, bulletin boards, video room to carry out national sports culture lectures, cultural knowledge training and appreciation activities, through those activities make the national sports culture popularized and promoted effectively.

Government is the main organization to protection of culture, which plays a vital role in protection of minority traditional sports culture. If there is no policy support, the national sports culture will be unlimited marginalization. It can be said that the establishment of the government led mechanism, means that the government has responsibility to protection and construction of the national traditional sports culture. This requires the government to the relevant data mining, collection, collation and research, put the necessary special funds for the protection of the rescue. Especially the protection of outstanding projects, the national traditional sports culture, and its descendants stunt; with audio and video, text and other forms, the things in static or dynamic mode of reproduction; the further development of the overall planning of the protection of national sports culture, strengthen legislation, clear the legal status of the protection of national sports culture. The protection、 inheritance and development mechanism of minority sports culture is the core and the foundation. The minority sports culture comes from ancient times. Today, the traditional national sports culture can be handed down from age to age, one of the most important reason is the mechanism of their long formed a complete set of local national sports culture self -protection and self-generation and self-development. This mechanism is rooted in the national growth of the land, with the first became quite reasonable, facing minority national sports culture environment is more complex, from all aspects of the impact, the development mechanism of protection and inheritance of ethnic minority traditional sports culture becomes more and more important.

how many years, the heritage of national traditional sports cultural are through teaching style, most of them have not recorded in the national traditional sports of the governments, especially at present there is no successor to heritage traditional sports culture, governments should increase investment, and actively carry out the collection of traditional ethnic sports, on the verge of disappearing of traditional sports, preserved with text and pictures form. In order to develop and promote good base in the future of traditional sports. The excavation and protection work can provide a more diverse selection for the national fitness movement, provides good cultural foundation for the development of the national fitness campaign.

Natural tourism and cultural tourism are the basic concepts of modern tourism. Especially in ethnic minority areas, the natural environment in the development of tourism. At the same time, distinctive characteristics of folk custom tourism products should actively developed, promote and inherit the national traditional sports. Many successful experience tells us that the national traditional sports and local tourism effectively is the combination of the forms and methods of development and promotion of national traditional sports heritage, some minority areas bring national traditional sports into the tourism project, and let the tourists participate. These ethnic traditional sports become a large number of tourists experience the rich ethnic customs experience a tour new magic and fitness entertainment. On the one hand, it shows the national traditional sports is 
conducive to protection、 inheritance and development of national traditional sports. On the other hand, the traditional sports of ethnic minorities has been developed and utilized to promote the development of local economy.

The ethnic minority should vigorously develop the Tourism Festival on the basis of national traditional sports, promoting cultural exchanges between different nationalities, protection of the national traditional sports through a variety of ways, through summing up to find suitable for the traditional ethnic sports, innovation the ethnic minorities traditional sports project. To speed up the innovation of traditional sports, means that the main innovation in the view of culture, cultural concept and cultural construction ideas on the transformation and progress, the need to abandon the traditional cultural conservatism, resist cultural modernization and promote radicalism, fusion and integration of cultural innovation, this approach can improve the specific symbol in cultural representation, which can keep the traditional sports culture essence and core value.

\section{Conclusion}

In the background of development of Chinese socio-cultural environment, correctly understanding of heritage and development ethnic minorities traditional sports culture, taking feasible measures to solve existing problems. On the one hand, it is conducive to the rapid development of Chinese traditional sports; on the other hand, it is beneficial to enhance Chinese socio-cultural environment.

\section{References:}

[1]Zhao Q E, Wen-Xiong W U. Countermeasures of Developing Vocational-technical Education in Ethnic Minority Regions[J]. Ethnic Education Study, 2003.

[2] Dong H. Study on the Problems and Countermeasures of Ethnic Minority Areas'College English Education[J]. Guizhou Ethnic Studies, 2013.

[3] Ran Q, Zhibin Q U. On Strategies of Inheritance and Development for Traditional Minority National Sports in the South of Guizhou Province[J]. Journal of Changsha University, 2014.

[4] Chang W F, Tourism D O, University K. Study on the Development Strategy of Henan Cultural Tourism Industry in the Creative Perspective[J]. Journal of Kaifeng University, 2015.

[5] Wang J. On Current Problems in the Development of Ethnic Culture and Education with Countermeasures[J]. Journal of Research on Education for Ethnic Minorities, 2010. 